\title{
Oncology drugs for orphan indications: how are HTA processes evolving for this specific drug
} category?

\author{
Elizabeth M Adkins' \\ Lindsay Nicholson' \\ David Floyd' \\ Mark Ratcliffe' \\ Helene Chevrou-Severac ${ }^{2}$ \\ 'PHMR, London, UK; ${ }^{2}$ Takeda \\ Pharmaceuticals AG, Zurich, \\ Switzerland
}

This article was published in the following Dove Press journal:

ClinicoEconomics and Outcomes Research

10 June 2017

Number of times this article has been viewed

\begin{abstract}
Orphan drugs (ODs) are intended for the diagnosis, prevention, or treatment of rare diseases. Many cancer subtypes, including all childhood cancers, are defined as rare diseases, and over one-third of ODs are now intended to treat oncology indications. However, market access for oncology ODs is becoming increasingly challenging; ODs are prone to significant uncertainty around their cost-effectiveness, while payers must balance the need for these vital innovations with growing sensitivity to rising costs. The objective of this review was to evaluate different mechanisms that have been introduced to facilitate patient access to oncology ODs in five different countries (Australia, Canada, England, France, and Sweden), using eight oncology ODs and non-orphan oncology drugs as examples of their application. A targeted literature review of health technology assessment (HTA) agency websites was undertaken to identify country-specific guidance and HTA documentation for recently evaluated oncology ODs and non-orphan oncology drugs. None of these countries were found to have explicit HTA criteria for the assessment of ODs, and therefore, oncology ODs are assessed through the usual HTA process. However, distinct and additional processes are adopted to facilitate access to oncology ODs. Review of eight case-study drugs showed that these additional assessment processes were rarely used, and decisions were largely driven by proving cost-effectiveness using standard incremental cost-effectiveness ratio (ICER) thresholds. The predominant implication arising from this study is that application of standard HTA criteria to oncology ODs in many countries fails to take into account any uncertainties around their clinical- and cost-effectiveness, resulting in disparities in HTA reimbursement decisions based on differences in addressing or accepting uncertainty. In order to address this issue, HTA agencies should adopt a more flexible approach to cost-effectiveness, as typified by the Tandvårds-och Läkemedelsförmånsverket in Sweden, which takes into account the small patient numbers involved, limited budget impact, and high unmet medical needs.
\end{abstract}

Keywords: orphan drugs, health technology assessment, oncology, rare cancers

\section{Introduction}

Health technology assessment (HTA) is a multidisciplinary, systematic process to evaluate the social, economic, organizational, and ethical issues of a health intervention or health technology in order to inform policy decision making ${ }^{1}$ and enable rational decisions to be made for healthcare resource allocation. ${ }^{2}$ Although HTA processes are based on internationally recognized methods, significant disparities have been observed in the outcomes of HTAs and recommendations made by HTA agencies, ${ }^{3-12}$ which finally results in inequities in access to important medicines between countries. ${ }^{13}$ This is exemplified in the field of orphan drug (OD) HTA and reimbursement.
Correspondence: Elizabeth M Adkins The Core, Science Central, Bath Lane, Newcastle upon Tyne, NE4 5TF, UK

Tel +44203432 745I

Fax +44 I9I 495730 I

Email elizabethadkins@phmr.com 
ODs are medicinal products intended for diagnosis, prevention, or treatment of rare diseases. In Europe, rare, or orphan, diseases are defined as life-threatening or chronically debilitating diseases with a prevalence of 1 in 2,000 individuals, ${ }^{14}$ whereas in Australia, a rare disease is one that affects $<2,000$ patients (prevalence of $<0.11$ per thousand people). ${ }^{15}$ An increased knowledge of cancer heterogeneity at the molecular level has resulted in those cancers that were previously recognized to be common, such as breast cancer and lung cancer, to be divided into rarer subtypes, thereby falling under the classification of a rare disease and making those drugs that target these subtypes, ODs. This has resulted in many cancer subtypes, including all cancers affecting children, being defined as rare diseases, ${ }^{16,17}$ and now over one-third of ODs are intended to treat oncology indications (termed oncology ODs). ${ }^{18}$ As such, oncology ODs represent a significant burden on healthcare budgets, and market access for these drugs is becoming more challenging as payers struggle to balance the need for these vital innovations with growing sensitivity to the rising costs. ${ }^{19}$

A further challenge to market access is the assessment criteria by which oncology ODs are appraised. Some countries have introduced specific agencies and/or criteria with which to appraise oncology drugs or ODs and have set alternative criteria and exceptions to the usual HTA framework, for example, England, Canada, and Australia. Also, there may be some form of risk-sharing agreement for high-value drugs, or performance- or outcome-based agreements. ${ }^{20}$ However, not all countries adopt this type of approach, and there is a significant variability in which oncology ODs are assessed. ${ }^{3}$

In countries that do not have alternative HTA criteria for oncology or ODs, ODs are prone to significant uncertainty around their cost-effectiveness, which makes HTA processes more difficult and subject to interpretation in each setting. This uncertainty arises due to the limited and/or incomplete evidence that is usually available to assess the value of the OD, which in turn reflects the small patient population limiting the size and statistical power of clinical trials. This issue is also hindered by ODs often receiving early marketing authorization before all the evidence usually required for reimbursement submissions is available, despite drugs for oncology indications granted orphan designation at a more advanced stage of development compared with drugs for non-oncology rare conditions. ${ }^{21}$ Ambiguity regarding costeffectiveness is particularly relevant for those rare diseases where the price premium of the drug may not be captured by the usual clinical evidence study format requested by HTA agencies, due to the difficulties in finding enough patients for clinical trials. Finally, this may result in limitations in determining with certainty whether a drug offers value for money. ${ }^{2}$

A thorough understanding of the possible HTA routes and the criteria with which oncology ODs are appraised in the countries in which reimbursement is sought is necessary to avoid the potential pitfalls that threaten a negative recommendation. Thus, the aim of this study was to understand the HTA processes applicable to oncology ODs, and whether they are treated as an oncology drug, an OD, or assessed through the usual HTA process in five countries with distinct HTA processes and publicly available information. The countries selected were Australia, Canada, England, France, and Sweden. To evaluate the assessment criteria, reimbursement decisions, and how uncertainties around clinical- and costeffectiveness are addressed in these countries, four case-study drugs were selected in each of the areas of orphan oncology and non-orphan oncology and a comparative analysis of the outcomes was carried out.

\section{Methods}

A pragmatic literature review and review of HTA agency websites were conducted to identify any literature or guidance relating to HTA decision-making criteria for orphan oncology and non-orphan oncology drugs in the target countries. Australia, Canada, England, France, and Sweden were selected as a representation of different HTA reimbursement appraisal criteria, including assessment of clinical- and cost-effectiveness, used in countries with publicly available information.

Eight drugs with HTAs conducted within the last 5 years were selected to give four case studies in each of the areas of orphan oncology and non-orphan oncology. The drugs were selected to ensure coverage of various tumor sites, mechanisms of action, and routes of administration. The selected orphan oncology case studies were obinutuzumab, ibrutinib, olaparib, and ramucirumab, and the selected nonorphan oncology case studies were nivolumab, ipilimumab, pertuzumab, and abiraterone. Each drug was assessed by at least three of the five HTA agencies. The selected casestudy drugs and their indications are summarized in Table 1. The following HTA websites were searched: www.pbs.gov. au (Australia), www.cadth.ca (Canada), www.has-sante. fr (France), www.nice.org.uk (England), and www.tlv.se, (Sweden).

\section{Results}

Table 2 summarizes the HTA process for each country. None of the five countries assessed had explicit HTA criteria with 
Table I Drug case studies

\begin{tabular}{|c|c|c|c|}
\hline Drug & Indication $^{\mathrm{a}}$ & Manufacturer & EMA MA date \\
\hline \multicolumn{4}{|l|}{ Orphan oncology } \\
\hline Gazyvaro ${ }^{\circledast}$ & CLL: & Roche Registration & July 23,2014 \\
\hline obinutuzumab ${ }^{91}$ & $\begin{array}{l}\text { Gazyvaro }{ }^{\circledast} \text { in combination with chlorambucil is indicated for the treatment } \\
\text { of adult patients with previously untreated CLL and with comorbidities } \\
\text { making them unsuitable for full-dose fludarabine-based therapy }\end{array}$ & $\begin{array}{l}\text { Ltd, Welwyn Garden } \\
\text { City, UK }\end{array}$ & \\
\hline Imbruvica ${ }^{\circledast} /$ ibrutinib $^{92}$ & $\begin{array}{l}\text { CLL: } \\
\text { Imbruvica }{ }^{\circledR} \text { is indicated for the treatment of adult patients with CLL } \\
\text { who have received at least one prior therapy, or in first line in the } \\
\text { presence of } 17 p \text { deletion or TP53 mutation in patients unsuitable for } \\
\text { chemoimmunotherapy }\end{array}$ & $\begin{array}{l}\text { Janssen-Cilag } \\
\text { International N.V., } \\
\text { Beerse, Belgium }\end{array}$ & $\begin{array}{l}\text { October 2I, } \\
2014\end{array}$ \\
\hline Lynparza ${ }^{\circledR} /$ olaparib ${ }^{93}$ & $\begin{array}{l}\text { Ovarian cancer: } \\
\text { Lynparza }^{\circledR} \text { is indicated as monotherapy for the maintenance treatment of } \\
\text { adult patients with platinum-sensitive relapsed BRCA-mutated (germline } \\
\text { and/or somatic) high-grade serous epithelial ovarian, fallopian tube, or } \\
\text { primary peritoneal cancer who are in response (complete response or } \\
\text { partial response) to platinum-based chemotherapy }\end{array}$ & $\begin{array}{l}\text { AstraZeneca AB, } \\
\text { Södertälje, Sweden }\end{array}$ & $\begin{array}{l}\text { December 16, } \\
2014\end{array}$ \\
\hline $\begin{array}{l}\text { Cyramza }^{\circledR} / \\
\text { ramucirumab }^{94}\end{array}$ & $\begin{array}{l}\text { Gastric/gastro-esophageal cancer: } \\
\text { Cyramza }{ }^{\circledR} \text { is a single agent or in combination with paclitaxel, it is indicated for } \\
\text { the treatment of adult patients with advanced gastric cancer or gastro- } \\
\text { esophageal junction adenocarcinoma with disease progression after prior } \\
\text { platinum and fluoropyrimidine chemotherapy }\end{array}$ & $\begin{array}{l}\text { Eli Lilly Nederland } \\
\text { B.V, Utrecht, the } \\
\text { Netherlands }\end{array}$ & $\begin{array}{l}\text { December 19, } \\
2014\end{array}$ \\
\hline \multicolumn{4}{|c|}{ Non-orphan oncology } \\
\hline Opdivo ${ }^{\circledR} /$ nivolumab 95 & $\begin{array}{l}\text { NSCLC: } \\
\text { Opdivo }{ }^{\circledR} \text { is indicated for the treatment of locally advanced or metastatic } \\
\text { squamous NSCLC after prior chemotherapy in adults }\end{array}$ & $\begin{array}{l}\text { Bristol-Myers } \\
\text { Squibb Pharma } \\
\text { EEIG, Uxbridge, UK }\end{array}$ & June 19,2015 \\
\hline Yervoy $^{\circledR} /$ ipilimumab 96 & $\begin{array}{l}\text { Melanoma: } \\
\text { Yervoy }{ }^{\circledR} \text { is indicated for the treatment of advanced (unresectable or } \\
\text { metastatic) melanoma in adults }\end{array}$ & $\begin{array}{l}\text { Bristol-Myers } \\
\text { Squibb Pharma } \\
\text { EEIG }\end{array}$ & July 13,2011 \\
\hline Perjeta ${ }^{\circledR} /$ pertuzumab ${ }^{97}$ & $\begin{array}{l}\text { Metastatic breast cancer: } \\
\text { Perjeta }{ }^{\circledR} \text { is indicated for use in combination with trastuzumab and } \\
\text { docetaxel in adult patients with HER2-positive metastatic or locally } \\
\text { recurrent unresectable breast cancer, who have not received previous anti- } \\
\text { HER2 therapy or chemotherapy for their metastatic disease }\end{array}$ & $\begin{array}{l}\text { Roche Registration } \\
\text { Limited }\end{array}$ & March 4, 2013 \\
\hline Zytiga ${ }^{\circledR} /$ abiraterone ${ }^{98}$ & $\begin{array}{l}\text { Prostate cancer: } \\
\text { Zytiga }{ }^{\circledR} \text { is indicated for the treatment of metastatic castration-resistant } \\
\text { prostate cancer in adult men who are asymptomatic or mildly symptomatic, } \\
\text { after failure of androgen deprivation therapy, in whom chemotherapy is not } \\
\text { yet clinically indicated }\end{array}$ & $\begin{array}{l}\text { Janssen-Cilag } \\
\text { International N.V. }\end{array}$ & $\begin{array}{l}\text { September } 5 \text {, } \\
2011\end{array}$ \\
\hline
\end{tabular}

Note: aSource: http://www.ema.europa.eu/.

Abbreviations: CLL, chronic lymphocytic leukemia; NSCLC, non-small cell lung cancer; EMA MA, European Medicines Agency Marketing Authorization.

which to assess ODs. However, each country operates a distinct and/or additional assessment process to facilitate patient access to oncology ODs, as described in more detail, by country, below.

All the HTA reports identified for the eight case studies included assessment of the clinical- and cost-effectiveness of the drug, with the exception of those from France where economic reports for a subset of drugs identified are currently underway. The impact on society was not found to have been specifically considered for either orphan oncology or non-orphan oncology drugs that were assessed by any HTA agency, although some patient expert testimonials were considered. The results of the HTA assessments are summarized in Table 3.

\section{Australia}

HTA processes relevant to orphan oncology drugs

In Australia, a centralized review body, the Pharmaceutical Benefits Advisory Committee (PBAC) makes national funding decisions for the Australian public healthcare system under the Pharmaceutical Benefit Scheme (PBS) positive formulary. ${ }^{22}$ The PBAC sometimes assesses ODs separately from non-ODs based on very strict criteria as part of the Life Saving Drugs Programme (LSDP), which provides one pathway in which 
Table 2 Country-specific processes for ODs

\begin{tabular}{|c|c|c|c|c|c|}
\hline & Australia, PBAC & Canada, CADTH & England, NICE & $\begin{array}{l}\text { France, HAS/ } \\
\text { CEPS/CT }\end{array}$ & $\begin{array}{l}\text { Sweden, } \\
\text { TLV }\end{array}$ \\
\hline $\begin{array}{l}\text { HTA criteria } \\
\text { specific to ODs? }\end{array}$ & $\begin{array}{l}\text { No } \\
\text { Apart from LSDP, which } \\
\text { requires drugs to meet strict } \\
\text { criteria }\end{array}$ & $\begin{array}{l}\text { Not nationally } \\
\text { Five provinces have } \\
\text { established processes } \\
\text { for DRD reimbursement } \\
\text { Ontario's DRD evaluation } \\
\text { framework is the best } \\
\text { defined }\end{array}$ & $\begin{array}{l}\text { No } \\
\text { However, NICE HST } \\
\text { section for appraising } \\
\text { ultra-ODs; no explicit } \\
\text { remit for ODs }\end{array}$ & No & No \\
\hline $\begin{array}{l}\text { HTA criteria } \\
\text { specific to } \\
\text { oncology? }\end{array}$ & No & $\begin{array}{l}\text { HTA is carried out by the } \\
\text { PCODR, which sits within } \\
\text { the CADTH. The pCODR } \\
\text { applies in all provinces } \\
\text { except Quebec, which } \\
\text { has separate advisory } \\
\text { committee that focuses on } \\
\text { cancer drugs (INESS) }\end{array}$ & No & No & No \\
\hline $\begin{array}{l}\text { Specific OD } \\
\text { committee? }\end{array}$ & No & Not nationally & $\begin{array}{l}\text { No } \\
\text { However, the HST } \\
\text { Evaluation Committee } \\
\text { exists for ultra-ODs }\end{array}$ & No & No \\
\hline $\begin{array}{l}\text { Separate budget } \\
\text { for ODs? }\end{array}$ & $\begin{array}{l}\text { No } \\
\text { There are potential options } \\
\text { for OD funding through the } \\
\text { LSDP for small number of } \\
\text { very rare life-threatening } \\
\text { conditions }\end{array}$ & No & $\begin{array}{l}\text { No } \\
\text { There is potential } \\
\text { funding for oncology } \\
\text { ODs through the } \\
\text { CDF }\end{array}$ & No & No \\
\hline Other notes & $\begin{array}{l}\text { The "rule of rescue" } \\
\text { may be applied as a } \\
\text { supplement to OD } \\
\text { submissions; however, } \\
\text { the rule does not replace } \\
\text { consideration of evidence-based } \\
\text { comparative cost-effectiveness. } \\
\text { There may } \\
\text { be potential to gain access } \\
\text { to oncology ODs and } \\
\text { oncology drugs under the } \\
\text { Highly Specialized Drugs } \\
\text { program and the Efficient } \\
\text { Funding of Chemotherapy } \\
\text { program of Section } 100 \text { of } \\
\text { National Health Act } 1953\end{array}$ & $\begin{array}{l}\text { Canada is in the process } \\
\text { of developing an OD } \\
\text { regulatory framework } \\
\text { Canadians have been } \\
\text { able to access some ODs } \\
\text { through Health Canada's } \\
\text { Special Access Programme }\end{array}$ & $\begin{array}{l}\text { In 20I4, NHS } \\
\text { England published a } \\
\text { statement of intent } \\
\text { used to inform the } \\
\text { development of a } \\
\text { 5-year strategy for } \\
\text { specialized services } \\
\text { for patients with rare } \\
\text { diseases }^{\mathrm{a}}\end{array}$ & $\begin{array}{l}\text { France has } \\
\text { had a National } \\
\text { Plan for Rare } \\
\text { Diseases since } \\
2005 \text { with } \\
\text { priorities } \\
\text { including } \\
\text { continuing } \\
\text { efforts in favor } \\
\text { of ODs }\end{array}$ & $\begin{array}{l}\text { Sweden } \\
\text { has greater } \\
\text { flexibility in } \\
\text { accepting } \\
\text { higher ICERs } \\
\text { depending } \\
\text { upon the level } \\
\text { of unmet need } \\
\text { and disease } \\
\text { severity }\end{array}$ \\
\hline
\end{tabular}

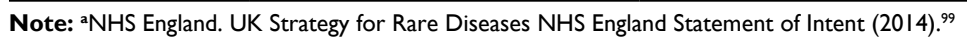

Abbreviations: CADTH, Canadian Agency for Drugs and Technologies in Health; CDF, Cancer Drugs Fund; CEPS, Comité Économique des Produits de Santé [Economic Committee for Health Products]; DRD, drugs for rare diseases; HAS, Haute Autorité de Santé [High Authority of Health]; HST, Highly Specialised Technology; HTA, health technology assessment; ICER, incremental cost-effectiveness ratio, INESS, Institut national d'excellence en santé et en services sociaux [National Institute of Excellence in Health and Social Services]; LSDP, Life Saving Drug Programme; NHS, National Health Service; NICE, National Institute for Health and Care Excellence; OD, orphan drug; PBAC, Pharmaceutical Benefits Advisory Committee; pCODR, pan-Canadian Oncology Drug Review; CT, Commission de la Transparence [Transparency Commission]; TLV, Tandvårds-och Läkemedelsförmånsverket [Dental and Pharmaceutical Benefits Agency].

subsidized access for ODs is granted. This operates outside the PBS to provide funding for a small number (currently 12 medicines for the treatment of eight conditions ${ }^{23}$ ) of "ultraorphan" life-saving drugs found to be clinically effective but whose listing is rejected by the PBAC due to failing required cost-effectiveness criteria, providing the drug meets strict criteria. ${ }^{24}$ The PBS also provides specific funding for patients treated in public hospitals for certain high-cost drugs, but there is no special explicit consideration of ODs. Submissions for a drug to be considered for inclusion in the LSDP must be lodged in conjunction with submissions to the PBAC for PBS listing. In addition, the Chief Medical Officer advises 


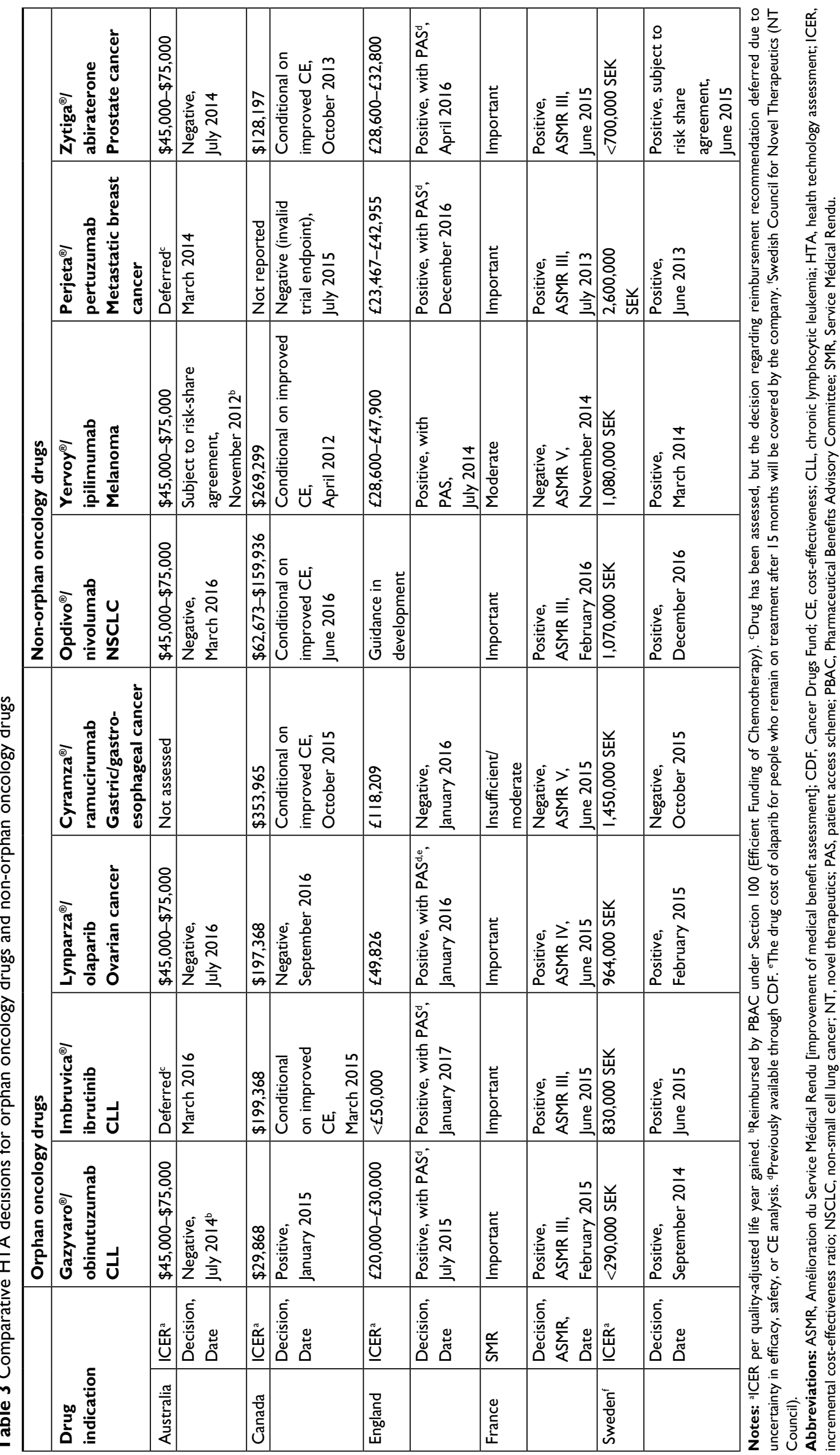


the Minister for Health on drugs proposed to be included in the LSDP. For LSDP in Australia (following the rejection of PBAC due to cost-effectiveness), the initial PBAC submission stands, and the only additional economic requirement is to indicate if the drug has been previously rejected for PBS listing due to failing cost-effectiveness criteria. A second pathway in which access to oncology ODs may be granted is under Section 100 of the National Health Act 1953 subsidized by the PBS. Several programs exist under this section, including the Highly Specialised Drugs Program and the Efficient Funding of Chemotherapy program, both of which list drugs for orphan oncology and oncology indications.

In addition, PBAC guidelines set out criteria for a "rule of rescue" (the value of rescuing life irrespective of cost), which allows more flexibility and may be applied as a supplement to OD submissions. The following four factors need to be applied concurrently for the "rule of rescue" to be invoked":

1. There are no drug or non-drug treatments available in Australia for patients with the specific medical condition.

2. The medical condition is severe, progressive, and expected to result in premature death.

3. The medical condition applies to a very small number of patients.

4. The proposed drug qualifies as a rescue from the condition by providing worthwhile clinical improvement.

However, the rule does not replace consideration of evidence-based comparative cost-effectiveness. In this situation, if PBAC concludes that the rule is relevant, it will then consider whether it is sufficiently influential to reverse a decision not to recommend listing.

Oncology drugs are subject to the same HTA process through PBAC and willingness-to-pay threshold as nononcology drugs. Australia has neither a specific fund for oncology medicines nor a separate set of guidelines, with the exception of the "herceptin program for late-stage metastatic breast cancer" case. Such a funding program, which was independent of the PBAC and PBS processes, has not been repeated yet and is not expected to be replicated in the future because it undermines the entire HTA approach. ${ }^{26}$

\section{HTA outcomes for oncology and non-oncology ODs in Australia}

In Australia, of the case studies that were reviewed, three orphan oncology drugs (obinutuzumab, ibrutinib, and olaparib) and four non-orphan oncology drugs (nivolumab, ipilimumab, pertuzumab, and abiraterone) have been assessed by PBAC (Table 3 ). Two of the orphan oncology drugs were not recommended due to failing to demonstrate cost-effectiveness, and the decision for the third was deferred due to uncertainty of the financial estimate. Two of the non-orphan oncology drugs were not recommended and did not demonstrate cost-effectiveness, whereas the decision for the third was deferred pending a judgment on the cost-effectiveness of all HER2 blocking medicines in metastatic breast cancer.

In all the PBAC public summary documents reviewed relating to the orphan oncology drugs, there was very little, if any, reference made to the orphan disease status. Obinutuzumab was not recommended by PBAC due to failing to demonstrate cost-effectiveness; ${ }^{27}$ however, it was recommended by the PBAC following a re-submission under Section $100 .^{28}$ Olaparib was rejected for use in the treatment of ovarian cancer following a minor resubmission to the PBAC based on the uncertainty of the overall survival results, and as such, the incremental cost-effectiveness ratio (ICER) was considered to have been substantially underestimated and would be unacceptably high when corrected. ${ }^{29}$ The decision to reimburse ibrutinib for second-line treatment in chronic lymphocytic leukemia was deferred based on the uncertainty of the financial estimates. ${ }^{30}$ The PBAC considered that in order for ibrutinib to be considered cost-effective in a future resubmission, the ICER should be between $\$ 50,000$ and $\$ 60,000$ per quality-adjusted life year (QALY).

A reimbursement decision for three of the four nonorphan oncology drugs in Australia had been made at the time of writing. The PBAC decided not to recommend that nivolumab be listed in the PBS for the treatment of squamous non-small cell lung cancer (NSCLC) on the basis that acceptable cost-effectiveness had not been adequately demonstrated and that the ICER of \$45,000-\$75,000 per QALY was likely to be significantly underestimated due to several concerns regarding the economic model. ${ }^{31}$ The PBAC gave a positive recommendation for ipilimumab, based on an ICER in the same range of $\$ 45,000-\$ 75,000$ under Section $100 .^{32}$ This recommendation was subject to a number of conditions, namely the drug is recommended where there is a high clinical need with no other effective therapies available, and subject to risk-share arrangements in which the appropriate use of ipilimumab, the maintenance of its cost-effectiveness, and the management of financial risk would be addressed by the sponsor. The PBAC rejected the submission to extend the PBS listing of abiraterone to include treatment of asymptomatic patients after failure of androgen deprivation therapy because the comparator was inappropriate, the subgroup analysis was not considered the most relevant patient group for PBS eligibility, and the ICER was deemed too high. ${ }^{33}$ No 
decisions to date have been made by PBAC for pertuzumab. The PBAC deferred making a recommendation on listing pertuzumab to enable it to first consider, establish, and accept the cost-effectiveness of trastuzumab for the treatment of metastatic breast cancer, before making a judgment on the cost-effectiveness of all HER2 blocking medicines in metastatic breast cancer, including pertuzumab. ${ }^{34}$

\section{Canada}

\section{HTA processes relevant to orphan oncology drugs}

In Canada, two centralized drug review processes exist: the Common Drug Review (CDR) for non-oncology drugs and the pan-Canadian Oncology Drug Review for oncology drugs (pCODR). ${ }^{35}$ All new drugs including ODs being considered for reimbursement through provincial (except for Quebec), territorial, or federal drug plans (ie, outpatient drugs) are evaluated by one of these processes. Both are managed by the Canadian Agency for Drugs and Technologies in Health (CADTH) and evaluate the clinical and economic implications of drugs submitted for review and provide reimbursement recommendations to participating drug plans.

In 2016, CADTH published a new recommendation framework that may have important implications for future OD reimbursement in Canada. ${ }^{36}$ Within this framework is the acknowledgement that in exceptional cases there may be "practical challenges in conducting robust clinical trials and pharmacoeconomic evaluations" and a significant unmet medical need. In these situations, the drug expert committees of CADTH may now issue a recommendation to reimburse with clinical criteria and/or conditions.

Currently, there is no centralized separate reimbursement review process for ODs (termed "drugs for rare diseases," DRDs, in Canada). ${ }^{37}$ Following the review of new drugs through the CADTH CDR or the pCODR, reimbursement decisions are made at the provincial and territorial levels. All jurisdictions have general reimbursement processes, whereas five of ten Canadian provinces also have established processes for DRD reimbursement: British Columbia, Alberta, Saskatchewan, Ontario, and New Brunswick. Of these, Ontario has an evaluation framework to support its DRD reimbursement program, and the review of a drug under the DRD framework is more extensive than non-orphan review by the Ontario Committee to Evaluate Drugs. ${ }^{38}$ For DRDs in Ontario, cost-effectiveness is not considered, but budget impact and affordability are taken into consideration. ${ }^{37}$ Federal, provincial, and territorial governments have begun to examine ways to address issues and costs around ODs collaboratively using evidence-based approaches. ${ }^{39}$ These may build on current practices around managed entry/exit criteria, coverage with evidence building, and risk sharing.

Canadians have also been able to access some ODs through Health Canada's Special Access Programme (SAP). SAP provides access on a case-by-case basis to drugs that are otherwise unavailable for sale in Canada or drugs that do not have regulatory approval by Health Canada. Though not explicitly directed at ODs, the program provides access to drugs for serious or life-threatening conditions when conventional therapies have been considered and ruled out, have failed, are unsuitable, or are unavailable. ${ }^{40}$ Although these paths worked in the past, they are limited in both providing access to ODs and information gathering and sharing since they were not designed to address the unique challenges of rare diseases. ${ }^{41}$

\section{HTA outcomes for oncology and non-oncology ODs in Canada}

In Canada, the pCODR made reimbursement decisions for all eight of the case studies (Table 3). One of the orphan oncology drugs was recommended as it was found to be costeffective, two were recommended conditional on improved cost-effectiveness, and one was not recommended due to uncertainty in the clinical evidence. Three of the non-orphan oncology drugs were recommended conditional on improved cost-effectiveness, and one was not recommended due to the primary trial outcome being considered invalid.

For the orphan oncology case studies, the pCODR recommended funding of obinutuzumab, used in the treatment of CLL, as it was found to be cost-effective with an ICER of $\$ 29,868$. However, it warned that individual provinces would need to consider the potentially large budget impact. ${ }^{42}$ The second drug indicated for the treatment of CLL, ibrutinib, was recommended for funding conditional on the costeffectiveness being improved to an acceptable level, as it would not be considered at the submitted price (ICER of $\$ 199,368) .{ }^{43}$ Olaparib was not recommended for reimbursement based on the high level of uncertainty in the available clinical data and could not be considered cost-effective at the submitted ICER of $\$ 197,368 .^{44}$ The pCODR recommended funding ramucirumab when used in combination with paclitaxel, conditional on its cost-effectiveness being improved to an acceptable level, whereas it was rejected for use as a monotherapy. ${ }^{45}$

Reimbursement decisions were made for all four of the non-orphan oncology case studies in Canada by the pCODR. The Canadian final pCODR recommendation for nivolumab stated that it should be funded conditional 
on the cost-effectiveness being improved to an acceptable level. The pCODR considered that as there is a net clinical benefit of nivolumab, jurisdictions may consider pricing arrangements and/or cost structures that would improve the cost-effectiveness from an ICER of \$62,673-\$159,936 to a more acceptable level. ${ }^{46}$ Similarly, ipilimumab was recommended by the pCODR provided that the cost-effectiveness was improved, as at the current price it was not cost-effective compared with other therapies commonly used to treat the same indication (ICER of \$269,299). ${ }^{47}$ Abiraterone was also recommended by the pCODR provided that the costeffectiveness was improved from an ICER of $\$ 128,197 .{ }^{48}$ The pCODR did not recommend pertuzumab owing to an invalid primary outcome used as a surrogate marker making the ICER indeterminable. ${ }^{49}$

\section{England}

HTA processes relevant to orphan oncology drugs

The National Institute for Health and Care Excellence (NICE) technology appraisal guidance advises the National Health Service (NHS) in England on the clinical effectiveness, costeffectiveness, and service impact of new and emerging as well as established healthcare technologies. The National Institute for Health Research Horizon Scanning Research \& Intelligence Centre has a remit to identify key emerging health technologies that may have a significant impact on patients or the provision of health services for NICE to appraise. In England, ODs are not evaluated using any special HTA or reimbursement considerations ${ }^{50}$ and are appraised under the standard technology appraisal program. NICE bases its recommendation on clinical effectiveness and an assessment of the ICER of a new technology and how this compares to their cost per QALY threshold. ${ }^{51}$ Unique to NICE HTA appraisal is an explicitly defined cost-effectiveness threshold as they state a "maximum acceptable ICER of $£ 20,000-£ 30,000$ per QALY gained" while evaluating technologies, ${ }^{51}$ or up to $£ 50,000$ per QALY for end-of-life treatments. To increase the likelihood of a positive recommendation based on costeffectiveness, manufacturers can discount the cost of a drug through a patient access scheme (PAS).

Although no guidance for ODs exist, NICE has developed guidance for appraising drugs for "ultra-orphan" conditions defined as having a prevalence of $<1$ in 50,000 under the Highly Specialised Technology Programme (HSTP). ${ }^{52}$ This program adheres to the general principles of NICE in that it has topic selection, scoping, evaluation, and appeal. However, additional decision-making criteria are considered, including the nature of the condition, impact of the new technology on health, its impact on delivery of the specialized service, as well as value for money. ${ }^{52}$ In addition, if a drug is not reimbursed by NICE, an Individual Funding Request (IFR) can be made to seek public reimbursement. Although not specifically for ODs, technologies for ODs that have failed reimbursement are within the scope of the IFR. ${ }^{53}$

Since 2016, following the reform of the Cancer Drugs Fund (CDF) originally formed in 2011, new and old oncology drugs are subject to the same HTA process through NICE and willingness-to-pay threshold as non-oncology drugs. Thus, those oncology drugs, irrespective of orphan status, that receive a positive recommendation are not funded from a separate NHS budget. When drugs for oncology indications look promising, but the clinical- or cost-effectiveness evidence is not robust enough for routine use, NICE can now give a conditional recommendation for the drug to be made available to NHS patients through the CDF, a ring-fenced budget holder facilitating patient access to some promising cancer drugs. ${ }^{54}$ Drugs are funded for a limited period of time (maximum of 2 years) through the CDF, during which a managed access agreement between NHS England and the company is agreed outlining, 1) the outcomes that need to be collected in order to resolve the key areas of clinical uncertainty, and 2) the cost of the drug during the managed access period. The oncology drug will then undergo a rapid reconsideration review to decide whether it will be recommended for use in the NHS. ${ }^{55}$

\section{HTA outcomes for oncology and non-oncology ODs in England}

All four of the orphan oncology drug case studies and three of the four non-orphan oncology drugs had been reviewed by NICE at the time of writing (Table 3). Three of the orphan oncology and all three of the appraised non-orphan oncology drugs were recommended (with a PAS), whereas the fourth orphan oncology drug was not recommended as it was not considered cost-effective. It is noteworthy that five of the six drugs that received positive reimbursement by NICE had all been previously funded through the CDF.

For obinutuzumab, NICE considered an agreed PAS between the manufacturer and the Department of Health, which brought the ICER within the range considered to be cost-effective. ${ }^{56}$ Ibrutinib received a positive recommendation by NICE with the conclusion that the drug represented an important and cost-effective treatment in CLL, despite the base-case ICER being reported as being $\sim 50,000{ }^{57}$ NICE took several other considerations into account such as meeting the end-of-life criteria, the inclusion of a PAS, 
the level of innovation of this "first-in-class" treatment, and patient expert advocacy. Similarly, olaparib was given a positive recommendation with an ICER of $<£ 46,806$ as NICE concluded that there was sufficient evidence to suggest that olaparib met the end-of-life criteria. ${ }^{58}$ This was in addition to an agreed PAS in which the NHS pays for a patient's treatment with olaparib up to a certain time, with the company providing olaparib free-of-charge beyond that point and for as long as each individual patient continues to receive the drug. Ramucirumab was rejected for reimbursement by NICE based on lack of cost-effectiveness. ${ }^{59}$

Three of the four non-orphan oncology case studies had a reimbursement decision by NICE at the time of writing (Table 3), whereas nivolumab was still under evaluation. Ipilimumab received a positive recommendation by NICE as a cost-effective use of NHS resources, given the application of a PAS and satisfying end-of-life criteria. ${ }^{60}$ NICE recommended the use of pertuzumab for HER2-positive breast cancer despite the limited clinical trial evidence available following a discount to the price agreed with the company, thereby bringing the ICER within the range normally considered to be cost-effective at $£ 23,467-£ 42,955 .{ }^{61}$ NICE recommended abiraterone with an ICER $£ 28,600-£ 32,800$ for the use in prostate cancer. NICE took into account several considerations such as a commercial access arrangement agreed with NHS England that the drug offered a step change in treatment because it is an oral drug taken by patients at home and is associated with few adverse reactions, as well as fulfilling the criteria for consideration as a life-extending, end-of-life treatment. ${ }^{62}$

\section{France}

\section{HTA processes relevant to orphan oncology drugs}

In France, there are no specific criteria or exemptions applied by the Haute Autorité de Santé (HAS), the French HTA body, in the assessment of ODs; prices and reimbursement are set according to standard procedures applying to non-orphan technologies. Within the HAS, the Transparency Commission (Commission de la Transparence [CT]) provides scientific advice concerning the usefulness, interest, and appropriate use of drugs. Under the existing system of value assessment, the Service Medical Rendu (SMR) assesses the medical benefit and appraises whether the drug should be reimbursed and at what rate, and the Amelioration du Service Medical Rendu (ASMR) is graded based on the assessment versus relevant comparators by indication and/or therapeutic strategy. ${ }^{63}$ The clinical evidence used in the OD SMR rating is based on the same clinical evidence submitted for regulatory approval by the EMA, which may be limited to Phase II trials and literature reviews. ${ }^{53}$ Normally, the cost of the drug is not considered in determining reimbursement status. ${ }^{64}$

There is no specific OD fund in France; however, the medical benefit is considered proven if the total budget impact for the indication is $<30$ million. ${ }^{53}$ Manufacturers of innovative pharmaceuticals can benefit from a fast-track procedure that makes medicines available with minimum delay. ${ }^{2}$ Although these accelerated processes are not specific to ODs, it is probable that ODs will meet the criteria.

In 2004, France passed the Loi Relatif à la Santé Publique (Law relating to Public Health), which featured the National Plan for Rare Diseases with the main goal "to ensure equity in the access to diagnosis, to treatment and to provision of care for people suffering from a rare disease." ${ }^{65}$ The plan also directs the HAS to "ensure that rare diseases are reimbursed within the framework of long-term disorders (ALD)." ${ }^{65}$ The ALD framework is a list of 30 long-term chronic, debilitating illnesses, where patients suffering from them are reimbursed $100 \%$ for expensive medications and procedures. ${ }^{66}$ The integration of rare diseases into the framework has not included all orphan indications as the wording of the law suggests, and the HAS published a recommendation that orphan status is not the sole criteria for admission to the ALD list. ${ }^{67}$

France has the highest expenditure for cancer medicines across Europe, on par with the US. However, despite the presence of an HTA agency, there is a reluctance to encourage explicit rationing of oncology drugs to avoid denial of potentially life-saving drugs. Disease severity and drug efficacy are considered to be the main criteria driving assessment decision-making rather than cost-effectiveness, and reimbursement is possible despite the potential for significant budget impact. However, pharmaceutical legislation introduced in 2012 has attempted to curtail the budgetary impact by attempting to define indications for health economic evaluation for those drugs that have potential to have large budgetary consequences. ${ }^{68}$ Cost-effectiveness analysis was implemented in January 2014, with economic reports requested by the $\mathrm{HAS} / \mathrm{La}$ Commission évaluation économique et de santé publique (CEESP). CEESP is in charge of assessing innovative health technologies that are likely to impact the expenses of the statutory public health insurance, thereby limiting the analyses to those interventions with an ASMR clinical benefit level I-III; an expected turnover/revenue of the drug for all its indications $>€ 20$ million during the second full year of sales (although this threshold is subject to discretion by the HAS); and/or there will be a change in the healthcare delivery process. For those drugs 
with a European Medicines Agency (EMA) marketing authorization prior to 2014 and an ASMR level of I-III, a cost-effectiveness analysis will be required at reimbursement renewal. ${ }^{69,70}$

\section{HTA outcomes for oncology and non-oncology ODs in France}

In France, all the eight case studies had been assessed by the HAS, with three orphan oncology drugs and three nonorphan oncology drugs receiving positive recommendations, and one orphan oncology and one non-orphan oncology drug receiving negative recommendations.

The HAS-CT gave positive recommendations for orphan oncology drugs ibrutinib ${ }^{71}$ and obinutuzumab ${ }^{72}$ for inclusion on the list of medicines reimbursed by National Insurance based on the perceived importance of the clinical benefit. However, as both the drugs received an ASMR III rating and EMA marketing authorization was granted after 2014, economic evaluations by the HAS-CEESP are currently under review, and these drugs are accessible to patients under a Temporary Authorization for Use (ATU) until the economic review is finalized. Olaparib also received a positive recommendation, with the CT concluding that it conferred actual benefit to patients. ${ }^{73}$ France rejected the use of ramucirumab based on the conclusion that no additional benefit was found compared to the clinically relevant comparators. ${ }^{74}$

Of the non-orphan oncology case studies, the HAS-CT recommended nivolumab with a moderate improvement in actual benefit, considering the serious, life-threatening nature of NSCLC, efficacy/adverse effects, and the availability of alternative treatments. ${ }^{75}$ Nivolumab is currently accessible to patients under an ATU while an economic evaluation by the HAS-CEESP is underway before finalizing this recommendation. Ipilimumab failed to demonstrate any improvement in actual benefit and therefore received a negative recommendation by the HAS. ${ }^{76}$ The HAS-CT found that all data provided by the manufacturer were of a low level of evidence and that efficacy/safety needs to be confirmed by clinical trials of better methodological quality. The HAS recommended pertuzumab with a moderate improvement in actual benefit, considering the serious life-threatening disease, that the treatment has curative intent, the efficacy/adverse effects, that it is a firstline therapy, and the availability of alternative treatments. ${ }^{77}$ Similarly the HAS recommended abiraterone with a moderate improvement in actual benefit, considering the life-threatening nature of the disease, curative aim of treatment, high efficacy/ tolerability ratio, second-line treatment, and treatment alternatives. ${ }^{78}$ No economic evaluations are available for either pertuzumab (assessed in July 2013) or abiraterone (original assessment in 2012, indication extended in June 2015).

\section{Sweden \\ HTA processes relevant to orphan oncology drugs}

In Sweden, there are two key organizations involved in reimbursement and pricing, namely the Dental and Pharmaceutical Benefits Agency (Tandvårds-och Läkemedelsförmånsverket, TLV) and the Swedish Council for Novel Therapies (NT Council). The TLV makes national pricing and reimbursement decisions on which pharmaceutical and health technology products should be covered by the PBS, and the NT Council evaluates these new drug therapies and provides recommendations on their use to the county councils.

Although there are no specific HTA processes for ODs in Sweden there is flexibility in the decision-making process guided by an ethical platform consisting of three principles, which means a higher cost per QALY can be accepted when the disease severity is high or if there are few other treatments to choose from..$^{53}$ These three principles are:

- The human dignity principle: All individuals have equal value and rights.

- The needs-solidarity principle: Those with the most pressing medical needs should have more resources of the healthcare system.

- The cost-effectiveness principle: A reasonable relationship between costs and effects, measured as improved health and quality of life.

Sweden have neither a specific fund for oncology medicines nor a separate set of HTA guidelines. In 2009, and updated in 2015, the Swedish government initiated a national reform to standardize cancer patient pathways, ${ }^{79}$ with the 21 independent Swedish counties given a monetary incentive to implement it. This restructure aimed to reduce current waiting times, increase patient satisfaction with cancer care, and reduce regional inequalities. One of the key challenges to this approach is to ensure that patients with diseases other than cancer do not receive a lower priority and that the three principles of the ethical platform which guide medical prioritization are adequately respected and taken into account.

\section{HTA outcomes for oncology and non-oncology ODs in Sweden}

In Sweden, all the eight case studies had been assessed by the TLV with recommendations made by the NT Council (Table 3). All the case studies received a positive recommendation, apart from one non-orphan oncology drug that 
was recommended subject to a risk sharing agreement and one orphan oncology drug that was not recommended at its current price as it was not considered cost-effective.

Of the orphan oncology drugs, obinutuzumab was recommended for reimbursement based on cost-effectiveness and/or proven net clinical benefit (ICER of $<290,000$ SEK),$^{80}$ whereas ibrutinib was also recommended without any restrictions as it was shown to be cost-effective with an ICER of 830,000 SEK and greatly improves long-term health outcomes over current treatments in a hard-to-treat population with very high unmet need. ${ }^{81}$ Olaparib received a positive recommendation by the NT Council after consideration of the severity of the condition and that no other treatment options are available for the patients in question, despite the high ICER of 964,000 SEK per QALY gained. ${ }^{82}$ Ramucirumab was not considered cost-effective with an ICER of 1,450,000 SEK, and it was recommended that NT county councils refrain from treatment with ramucirumab at its current price. ${ }^{83}$

Non-orphan oncology drugs nivolumab ${ }^{84}$ and ipilim$u_{m a b}{ }^{85}$ were granted positive reimbursement decisions by the NT Council with ICERs $>1,000,000$ SEK. For nivolumab, a confidential discount was provided by the manufacturer, which was considered in the assessment with the likelihood that the cost-effectiveness would be improved. For ipilimumab, it was concluded that the need and solidarity principle justify the resources spent on drug treatments that may lead to prolonged survival for seriously ill patients. Pertuzumab was recommended following extensive discussions between the NT Council and the company to negotiate a lower price for the drug. ${ }^{86}$ The NT Council considered this to be acceptable and a balanced assessment of the benefits of drug and cost. The fourth non-orphan oncology drug, abiraterone, was recommended subject to a risk share agreement based on the uncertainty around the cost-benefit analysis. ${ }^{87}$

\section{Discussion}

A review of the HTA appraisal criteria in the five countries of interest, Australia, Canada, Sweden, France, and England, for either orphan oncology or non-orphan oncology drugs revealed that they are currently assessed in the same way as other drugs. In all the oncology OD appraisal case studies included, there was little, if any, reference to the orphan status of the disease, exemplifying that these drugs were subject to the same standard HTA appraisal process. This is not unexpected, as none of the countries included in this review currently have specific committees or separate budgets for oncology ODs or non-orphan oncology drugs, with the exception of the HST Evaluation Committee for appraising "ultra-orphan" drugs in England. In addition, none of these countries at present, except for Canada, have specific HTA processes for ODs or oncology indications at a national level.

Despite using the standard HTA appraisal process in each of the countries, there are often additional potential avenues in place which may facilitate access to oncology ODs and non-orphan oncology drugs. These include temporary reimbursement while additional evidence is collected (England, oncology drugs only), higher willingness-to-pay thresholds for end-of-life treatments (England), separate assessment criteria for ultra-ODs (England and Australia), the use of clinical criteria and/or conditions for reimbursement where there may be practical challenges in conducting robust clinical trials and pharmacoeconomic evaluations (Canada), and flexibility in the usual process (Sweden).

The use of these processes varied across the case studies, resulting in discrepancies in reimbursement decisions across the different countries (Table 3). In Australia, the LSDP and "rule of rescue" were not invoked for any of the drugs reviewed (with three drugs therefore not reimbursed). One orphan oncology drug that received a negative recommendation from PBAC was then reimbursed under Section 100 (Efficient Funding of Chemotherapy), and one non-orphan oncology drug was recommended subject to a risk-sharing agreement. In Sweden, the willingness-to-pay or the ICER threshold is different depending on the level of unmet need ${ }^{88}$ and higher degrees of uncertainty are accepted in the case of ODs. ${ }^{53}$ This resulted in positive recommendations for seven of eight of the drugs reviewed, with one non-orphan oncology drug recommended subject to a risk-share agreement, and one recommended following negotiation of a lower price for the drug. In England, although ODs are assessed under existing criteria, NICE has acknowledged that many ODs, in particular, those for "ultra-orphan" conditions, would have unacceptable ICERs if no special criteria or weightings were applied, resulting in a higher cost-effectiveness threshold accepted ( $£ 200,000-£ 300,000$ per QALY). However, as oncology ODs generally do not fall under the definition of "ultra-orphan," as illustrated by the case studies presented here, they will be subject to the threshold of $£ 20,000-£ 30,000$ per QALY gained, or up to $£ 50,000$ for those meeting end-of-life criteria. For drugs that are unlikely to meet cost-effectiveness criteria or there is considerable uncertainty on costs, manufacturers can propose a PAS to NICE, as illustrated by all six of the drugs that were recommended by NICE in the case studies reviewed. Similarly, in Canada, five of the six drugs that received a positive decision were conditional on cost-effectiveness being improved to an acceptable level. 
As expected, in the case studies reviewed, any perceived limitations in clinical evidence and economic evidence were likely to result in restrictions or decisions not to reimburse the orphan oncology drugs. For example, positive recommendations were given in Canada, Sweden, France, and England for the orphan oncology drugs obinutuzumab and ibrutinib for the treatment of CLL. In contrast, in Australia, obinutuzumab was only made available through Section 100 , with the PBAC acknowledging that there was a clinical need for treatment options in CLL, and reimbursement was deferred for ibrutinib based on a failure to demonstrate cost-effectiveness. In Canada, a positive recommendation of ibrutinib was conditional on "improving cost-effectiveness to an acceptable level" and in England, NICE accepted the higher ICER based on the drug satisfying end-of-life criteria. For olaparib, NICE granted a positive reimbursement on the condition that the drug cost for patients who remain on treatment after 15 months would be met by the company. Although the OD ramucirumab was rejected by three of the four HTA agencies that appraised it, TLV, HAS, and NICE, based on a failure to prove its cost-effectiveness, Canada approved this drug with the caveat that its cost-effectiveness is improved to an acceptable level.

This disparity in HTA decisions between countries was not limited to orphan oncology drugs as we also found clear differences in reimbursement of non-orphan oncology drugs. This was not unexpected given that both oncology OD and oncology drug assessments share similar decision drivers, such as clinical benefit and unmet need, which can be perceived differently. As with orphan oncology drugs, any perceived limitations in the submitted evidence were met with caveats placed on reimbursement. For example, the non-orphan oncology drugs ipilimumab and abiraterone were recommended subject to risk sharing agreement in Australia, as was abiraterone in Sweden. Positive recommendations of nivolumab and ipilimumab in Canada, as with ODs, were conditional on improved cost-effectiveness. However, in Canada, regional disparities may then occur as a result of differences in provincial decision-making processes ${ }^{89}$

In Australia, Canada, Sweden, and England, all HTA submissions included both clinical and cost-utility analysis, often with a budget impact analysis. Economic reports for France (evaluated by the CEESP) were not available for most of the assessments, likely because the ASMR rating was not high enough (III or above), the budget impact was not considered significant, or because HTA reviews were conducted pre-2014. However, the review of HTA processes highlighted how the access to the French drug market is being increasingly driven by data pertaining to comparative cost-effectiveness, particularly for drugs with a moderate or higher additional benefit and/or expected large budget impact. ${ }^{63} \mathrm{~A}$ cost-effectiveness or willingness-to-pay threshold often serves as a general decision rule for ascertaining value for money. ${ }^{64}$ Cost-effectiveness is very important in the decision-making process for Australia, Canada, and England, with assessments that a drug is not cost-effective, based on a strict ICER threshold, likely to result in an outright rejection or recommendations conditional on improvements in costeffectiveness to an "acceptable level." These findings are in line with a previous study based on a sample of 60 ODs, which reported that financial considerations and budget often impact influence on access to ODs, with nearly a quarter of 22 European countries surveyed restricting access to ODs due to budgetary constraints, five countries granted full access, whereas several other countries authorized access but with restrictions, for example, prior authorization. ${ }^{90}$ Therefore, in countries heavily reliant on the demonstration of costeffectiveness, ODs are not likely to achieve a positive recommendation by the standard HTA process. In contrast, although cost-effectiveness remains a key driver in the decision-making process in Sweden, the TLV takes a more flexible approach to the ICER threshold and, guided by the three principles of the ethical platform, may accept higher ICERs according to the perceived level of unmet medical need.

In conclusion, orphan oncology drugs in Australia, Canada, England, France, and Sweden are currently assessed through the standard HTA processes. However, the application of standard HTA criteria to orphan oncology drugs in Australia, Canada, England, and France fails to take into account the often more limited availability of clinical data and associated uncertainties around their clinical- and costeffectiveness, resulting in disparities in HTA reimbursement decisions based on differences in addressing or accepting uncertainty. Additional processes/criteria are available in some countries to provide access to orphan oncology drugs that would not be recommended through the usual process. A different approach has been taken in Sweden, where the usual HTA process involves a more flexible approach to cost-effectiveness that is more suited to assessment of ODs as decisions are influenced by the number of patients requiring treatment, having a limited budget impact, and the disease having high unmet medical needs. In order to address the conflict between standard HTA processes and positive reimbursement of orphan oncology drugs, HTA agencies should adopt a more flexible approach to cost-effectiveness, as typified by the TLV in Sweden. Further studies are required in this rapidly evolving field to inform future OD assessment using specific HTA process. 


\section{Acknowledgments}

This research was funded by Takeda Pharmaceuticals International GmbH, Zurich, Switzerland.

The abstract of this paper was presented at the International Society for Pharmacoeconomics and Outcomes Research, Vienna, Austria (2016) as a poster presentation with interim findings. The poster has been published online at https://www.ispor.org/research pdfs/54/pdffiles/PHP299.pdf.

\section{Author contributions}

All the authors have contributed substantially to the conception and design of the study and the acquisition, analysis, and interpretation of data. They have contributed in drafting the manuscript and revision for the final approval.

\section{Disclosure}

At the time of writing this manuscript, EMA, LN, DF, and MR were employed by PHMR London, UK and HCS was employed by Takeda Pharmaceuticals, Switzerland.

\section{References}

1. WHO. WHO | Health technology assessment; 2016. Available from: http://www.who.int/health-technology-assessment/en/. Accessed December 18, 2016.

2. Garau M, Mestre-Ferrandiz J. Access mechanisms for orphan drugs: a comparative study of selected European countries. OHE Brief. 2009 52:1-32.

3. Simoens S. Pricing and reimbursement of orphan drugs: the need for more transparency. Orphanet J Rare Dis. 2011;6:42.

4. G-BA. The benefit assessment of pharmaceuticals in accordance with the German Social Code, Book Five (SGB V), section 35a - Federal Joint Committee; 2011. Available from: http://www.english.g-ba.de/ benefitassessment/information/. Accessed January 11, 2017.

5. Hughes-Wilson W, Palma A, Schuurman A, Simoens S. Paying for the orphan drug system: break or bend? Is it time for a new evaluation system for payers in Europe to take account of new rare disease treatments? Orphanet J Rare Dis. 2012;7:74.

6. Roos JCP, Hyry HI, Cox TM. Orphan drug pricing may warrant a competition law investigation. BMJ. 2010;341:c6471.

7. European Commission. Clinical Added Value of Orphan Drugs (CAVOD); 2011. Available fom: http://ec.europa.eu/chafea/documents/ news/CAVOD_Final Report_vf_corrected_281011.pdf. Accessed December 15, 2016.

8. Denis A, Mergaert L, Fostier C, Cleemput I, Simoens S. A comparative study of European rare disease and orphan drug markets. Health Policy. 2010;97(2-3):173-179.

9. Collier J. The pharmaceutical price regulation scheme. BMJ. 2007; 334(7591):435-436.

10. Rawlins MD, Culyer AJ. National Institute for Clinical Excellence and its value judgments. BMJ. 2004;329(7459):224-227.

11. Barham L. Orphan medicines: special treatment required?; 2012. Available from: http://www.2020health.org/2020health/Publications/ publications-2012/Orphan-Drugs.html. Accessed December 15, 2016.

12. NICE. NICE highly specialised technologies guidance | NICE guidance; 2016. Available from: https://www.nice.org.uk/about/ what-we-do/our-programmes/nice-guidance/nice-highly-specialisedtechnologies-guidance. Accessed December 15, 2016.
13. Garrido MV, Kristensen FB, Nielsen CP, Busse R. Health technology policy-making in Europe current status, challenges and potential. WHO; 2008. Available from: http://www.euro.who.int/_data/assets/ pdf_file/0003/90426/E91922.pdf. Accessed December 10, 2016.

14. Kaplan W, Wirtz VJ, Mantel-Teeuwisse A, Stolk P, Duthey B, Laing R. Priority medicines for Europe and the World 2013 Update. Available from: http://www.who.int/medicines/areas/priority_medicines/MasterDocJune28_FINAL_Web.pdf. Accessed December 10, 2016.

15. Song P, Gao J, Inagaki Y, Kokudo N, Tang W. Rare diseases, orphan drugs, and their regulation in Asia: current status and future perspectives. Intractable rare Dis Res. 2012;1(1):3-9.

16. EURODIS. About rare diseases. Available from: http://www.eurordis. org/. Accessed January 11, 2017.

17. EURODIS. Rare diseases: understanding this public health priority; 2005. Available from: http://www.eurordis.org/IMG/pdf/princeps_document-EN.pdf. Accessed January 11, 2017.

18. EURODIS. Mapping out the similarities and differences between rare cancers and rare diseases; 2015. Available from: http://www.eurordis. org/sites/default/files/rare-cancers-2015-2016.pdf. Accessed January $11,2017$.

19. Cohen JP, Felix A. Are payers treating orphan drugs differently? J Mark Access Heal Policy. 2014:2.

20. Cheema PK, Gavura S, Migus M, Godman B, Yeung L, Trudeau ME. International variability in the reimbursement of cancer drugs by publically funded drug programs. Curr Oncol. 2012;19(3):e165-e176.

21. Pauwels K, Huys I, Casteels M, et al. Are products with an orphan designation for oncology indications different from products for other rare indications? A retrospective analysis of European orphan designations granted between 2002-2012. Orphanet J Rare Dis. 2017;12(1):36.

22. Morgan SG, McMahon M, Mitton C, et al. Centralized drug review processes in Australia, Canada, New Zealand, and the United kingdom. Health Aff (Millwood). 2006;25(2):337-347.

23. Australian Government Department of Health. Life Saving Drugs Program (LSDP). Available from: http://www.health.gov.au/lsdp. Accessed January 24, 2017.

24. Paris V, Belloni A. Value in pharmaceutical pricing country profile: Australia; 2014. Available from: https://www.oecd.org/health/Valuein-Pharmaceutical-Pricing-Australia.pdf. Accessed January 24, 2017.

25. PBAC. Guidelines for preparing submissions to the Pharmaceutical Benefits Advisory Committee (Version 4.5); 2015. Available from: https://pbac.pbs.gov.au/content/information/printable-files/pbacg-book. pdf. Accessed December 18, 2016.

26. Dranitsaris G, Papadopoulos G. Health technology assessment of cancer drugs in Canada, the United Kingdom and Australia: should the United States take notice? Appl Health Econ Health Policy. 2015;13(3):291-302.

27. PBAC. Pharmaceutical Benefits Scheme (PBS) $\mid$ Obinutuzumab, solution for IV infusion, $1000 \mathrm{mg} / 40 \mathrm{~mL}$, Gazyva ${ }^{\circledR}$, Roche Products Pty Ltd. 2014. Available from: http://www.pbs.gov.au/info/industry/listing/ elements/pbac-meetings/psd/2014-07/obinutuzumab-psd-07-2014. Accessed February 9, 2017.

28. PBAC. Pharmaceutical Benefits Scheme (PBS) $\mid$ Obinutuzumab; 1 g/40 $\mathrm{mL}$ injection, $40 \mathrm{~mL}$ vial; Gazyva ${ }^{\circledR} ; 2015$. Available from: https://www. pbs.gov.au/pbs/industry/listing/elements/pbac-meetings/psd/2015-03/ obinutuzumab-gazyva-psd-03-2015. Accessed December 21, 2016.

29. PBAC. Pharmaceutical Benefits Scheme (PBS) | Olaparib: $50 \mathrm{mg}$ capsule, 4 x 112 capsules, Lynparza $^{\mathrm{TM}}$; 2016. Available fom: http://www. pbs.gov.au/info/industry/listing/elements/pbac-meetings/psd/2016-07/ olaparib-psd-july-2016. Accessed January 24, 2017.

30. PBAC. Pharmaceutical Benefits Scheme (PBS) | Ibrutinib: $140 \mathrm{mg}$ capsules, 90, Imbruvica $^{\circledR} ; 2016$. Available from: https://www.pbs.gov. $\mathrm{au} / \mathrm{pbs} /$ industry/listing/elements/pbac-meetings/psd/2016-03/ibrutinibimbruvica-psd-03-2016. Accessed December 21, 2016.

31. Pharmaceutical Benefits Scheme (PBS) | Nivolumab: $40 \mathrm{mg}$ in $4 \mathrm{ml}$ $(10 \mathrm{mg} / \mathrm{mL}$ concentrate for IV infusion) $100 \mathrm{mg}$ in $10 \mathrm{~mL}(10 \mathrm{mg} / \mathrm{mL}$ concentrate for IV infusion), Opdivo ${ }^{\circledR} ; 2016$. Available from: http://www. pbs.gov.au/info/industry/listing/elements/pbac-meetings/psd/2016-03/ nivolumab-opdivo-non-sq-psd-03-2016. Accessed January 31, 2017. 
32. PBAC. Pharmaceutical Benefits Scheme (PBS) | Ipilimumab: $50 \mathrm{mg} / 10 \mathrm{~mL}$ injection, $10 \mathrm{~mL}, 200 \mathrm{mg} / 40 \mathrm{~mL}$ injection, $40 \mathrm{~mL}$, Yervoy $^{\circledR} ; 2016$. Available from: https://www.pbs.gov.au/pbs/industry/listing/elements/pbac-meetings/psd/2016-07/ipilimumab-psd-july-2016. Accessed December 21, 2016.

33. PBAC. Pharmaceutical Benefits Scheme (PBS) $\mid$ Abiraterone, tablet, $250 \mathrm{mg}$ (as acetate), Zytiga ${ }^{\circledR}$ - November 2012; 2012. Available from: https://www.pbs.gov.au/info/industry/listing/elements/pbac-meetings/ psd/2012-11/abiraterone. Accessed December 21, 2016.

34. PBAC. Pharmaceutical Benefits Scheme (PBS) | PERTUZUMAB, $420 \mathrm{mg} / 14 \mathrm{~mL}$ injection, 1 x $14 \mathrm{~mL}$ vial Perjeta ${ }^{\circledR}$, Roche Products Pty Ltd; 2014. Available from: https://www.pbs.gov.au/info/industry/listing/ elements/pbac-meetings/psd/2014-03/pertuzumab. Accessed December 21, 2016.

35. ISPOR. Pharmaceutical HTA and reimbursement processes - Canada; 2011. Available from: https://www.ispor.org/HTARoadMaps/CanadaPharm.asp. Accessed December 15, 2016.

36. McKesson Canada white paper. Towards a new way of evaluating orphan drugs at CADTH; 2016. Available from: https://www.canadianinstitute. com/wp-content/uploads/2016/07/Orphan-Drugs-at-CADTH_McKesson.pdf. Accessed December 19, 2016.

37. CADTH. Drugs for rare diseases: evolving trends in regulatory and health technology assessment perspectives (CADTH Environmental scan); 2016. Available from: https://www.canadianinstitute. com/wp-content/uploads/2016/07/Orphan-Drugs-at-CADTH_Mc Kesson.pdf. Accessed December 18, 2016.

38. O'Sullivan A. Should orphan drugs be subjected to value-based assessments?; 2012. Available from: https://www.ispor.org/meetings/ WashingtonDC0512/releasedpresentations/IP5-Sullivan.pdf. Accessed December 18, 2016.

39. Menon D, Clark D, Stafinski T. Reimbursement of drugs for rare diseases through the public healthcare system in Canada: where are we now? Healthc Policy. 2015;11(1):15-32.

40. Health Canada. Special Access to drugs and health products. 2013. Available from: http://www.hc-sc.gc.ca/dhp-mps/acces/drugs-drogues/ index-eng.php. Accessed February 9, 2017.

41. Health Canada. Regulatory initiative: regulations amending the food and drug regulations - orphan drugs - Forward Regulatory Plan 2016-2018 - Health Canada. 2016. Available from: http://www.hc-sc.gc.ca/ahcasc/legislation/acts-reg-lois/frp-ppr/2016-2018/odrd-momr-eng.php. Accessed February 9, 2017.

42. CADTH pCODR. Gazyva for chronic lymphocytic leukemia - Details | CADTH.ca; 2015. Available from: https://www.cadth.ca/gazyvachronic-lymphocytic-leukemia-details. Accessed December 21, 2016.

43. CADTH pCODR. Imbruvica for chronic lymphocytic leukemia/small lymphocytic lymphoma (previously treated) - details | CADTH.ca; 2015. Available from: https://www.cadth.ca/imbruvica-chronic-lymphocytic-leukemiasmall-lymphocytic-lymphoma-previously-treateddetails. Accessed December 21, 2016.

44. CADTH pCODR. Lynparza for ovarian cancer (2nd line) - details | CADTH.ca; 2015. Available from: https://www.cadth.ca/lynparzaovarian-cancer-2nd-line-details. Accessed January 24, 2017.

45. CADTH pCODR. Cyramza for advanced GC or GEJ adenocarcinoma - details | CADTH.ca; 2015. Available from: https://www.cadth.ca/ cyramza-advanced-gc-or-gej-adenocarcinoma-details. Accessed January 24, 2017.

46. CADTH pCODR. pCODR expert review committee final recommendation: nivolumab and NSCLC; 2016. Available from: https://www. cadth.ca/sites/default/files/pcodr/nivolumab_opdivo_nsclc_fn_rec.pdf. Accessed December 21, 2016.

47. CADTH pCODR. Yervoy for advanced melanoma - details $\mid$ CADTH. ca; 2012. Available from: https://www.cadth.ca/yervoy-advancedmelanoma-details. Accessed December 21, 2016.

48. CADTH pCODR. Zytiga for metastatic castration resistant prostate cancer - details | CADTH.ca; 2013. Available from: https://www.cadth.ca/ zytiga-metastatic-castration-resistant-prostate-cancer-details. Accessed January 24, 2017.
49. CADTH pCODR. Perjeta or perjeta-herceptin combo pack for neoadjuvant breast cancer - details | CADTH.ca; 2015. Available from: https:// www.cadth.ca/perjeta-or-perjeta-herceptin-combo-pack-neoadjuvantbreast-cancer-details. Accessed January 24, 2017.

50. Kawalec P, Sagan A, Pilc A. The correlation between HTA recommendations and reimbursement status of orphan drugs in Europe. Orphanet $J$ Rare Dis. 2016;11(1):122.

51. NICE. Guide to the methods of technology process; 2013. Available from: https://www.nice.org.uk/process/pmg9/resources/guide-to-themethods-of-technology-appraisal-2013-pdf-2007975843781. Accessed December 20, 2016.

52. NICE. National Institute for Care and Excellence interim process and methods of the highly specialised technologies programme principles; 2013. Available from: https://www.nice.org.uk/Media/ Default/About/what-we-do/NICE-guidance/NICE-highly-specialisedtechnologies-guidance/Highly-Specialised-Technologies-Interimmethods-and-process-statements.pdf. Accessed December 20, 2016.

53. Tordrup D, Tzouma V, Kanavos P. Orphan drug considerations in Health Technology Assessment in eight European countries. Rare Dis Orphan Drugs. 2014;1(3):83-97.

54. NICE. Technology appraisal processes - cancer drugs fund; 2016. Available from: https://www.nice.org.uk/Media/Default/About/what-we-do/ NICE-guidance/NICE-technology-appraisals/process-and-methodsguide-addendum.pdf. Accessed December 21, 2016.

55. NICE. Rapid re-consideration of drugs currently funded through the cancer drugs fund; 2016. Available from: https://www.nice.org.uk/ Media/Default/About/what-we-do/NICE-guidance/NICE-technologyappraisals/TA-CDF-reconsideration-process-March-2016-FINAL.pdf. Accessed January 30, 2017.

56. NICE. Obinutuzumab in combination with chlorambucil for untreated chronic lymphocytic leukaemia | guidance and guidelines | NICE; 2015. Available from: https://www.nice.org.uk/guidance/ta343. Accessed December 21, 2016.

57. NICE. Ibrutinib for previously treated chronic lymphocytic leukaemia and untreated chronic lymphocytic leukaemia with $17 \mathrm{p}$ deletion or TP53 mutation | guidance and guidelines | NICE; 2017. Available from: https://www.nice.org.uk/guidance/ta429. Accessed January 25, 2017.

58. NICE. Olaparib for maintenance treatment of relapsed, platinumsensitive, BRCA mutation-positive ovarian, fallopian tube and peritoneal cancer after response to second-line or subsequent platinum-based chemotherapy | guidance and guidelines | NICE; 2016. Available from: https://www.nice.org.uk/guidance/ta381. Accessed December 21, 2016.

59. NICE. Ramucirumab for treating advanced gastric cancer or gastrooesophageal junction adenocarcinoma previously treated with chemotherapy; 2016. Available from: https://www.nice.org.uk/guidance/ ta378/resources/ramucirumab-for-treating-advanced-gastric-cancer-orgastrooesophageal-junction-adenocarcinoma-previously-treated-withchemotherapy-82602795958981. Accessed December 21, 2016.

60. NICE. Ipilimumab for previously untreated advanced (unresectable or metastatic) melanoma | guidance and guidelines | NICE; 2014. Available from: https://www.nice.org.uk/guidance/ta319. Accessed December 21, 2016.

61. NICE. Pertuzumab for the neoadjuvant treatment of HER2-positive breast cancer | guidance and guidelines | NICE; 2016. Available from: https://www.nice.org.uk/guidance/ta424. Accessed December 21, 2016.

62. NICE. Abiraterone for treating metastatic hormone-relapsed prostate cancer before chemotherapy is indicated; 2016. Available from: https:// www.nice.org.uk/guidance/ta387/resources/abiraterone-for-treatingmetastatic-hormonerelapsed-prostate-cancer-before-chemotherapy-isindicated-82602854745541. Accessed December 21, 2016.

63. Remuzat C, Mondher T, Falissard B. New drug regulations in France: what are the impacts on market access? Part 1 Overview of new drug regulations in France. J Mark Access Heal Policy. 2013;1:20891.

64. Sorensen C, Drummond M, Kanavos P. Ensuring Value for Money in Health Care The Role of Health Technology Assessment in the European Union. WHO Regional Office for Europe: World Health Organization; 2008. 
65. Douste-Blazy P, Monchamp M-A, D'Aubert F. French National Plan for Rare Diseases 2005-2008. 2005;(November 2004):1-36.

66. Hossein Z, Gerard A. Trends in cost sharing among selected high income countries - 2000-2010. Health Policy. 2013;112(1-2):35-44.

67. HAS. Création d 'une ALD spécifique maladies rares; 2005. Available from: http://www.has-sante.fr/portail/upload/docs/application/pdf/ avis_ald_rapport.pdf. Accessed December 18, 2016.

68. Aggarwal A, Ginsburg O, Fojo T. Cancer economics, policy and politics: what informs the debate? Perspectives from the EU, Canada and US. J Cancer Policy. 2014;2(1):1-11.

69. Rémuzat C, Toumi M, Falissard B. New drug regulations in France: what are the impacts on market access? Part 2 - impacts on market access and impacts for the pharmaceutical industry. $J$ Mark Access Heal Policy. 2013;1.

70. Toumi M, Rémuzat C, El Hammi E, et al. Current process and future path for health economic assessment of pharmaceuticals in France. J Mark Access Heal Policy. 2015;3.

71. Haute Autorité de Santé TC. Haute Autorité de Santé - IMBRUVICA (ibrutinib), Bruton's tyrosine kinase (BTK) inhibitor; 2015. Available from: http://www.has-sante.fr/portail/jcms/c_2049868/en/imbruvicaibrutinib-bruton-s-tyrosine-kinase-btk-inhibitor. Accessed January 25, 2017.

72. Haute Autorité de Santé TC. Haute Autorité de Santé - GAZYVARO (obinutuzumab), type II humanised anti-CD20 recombinant monoclonal antibody; 2015. Available from: http://www.has-sante.fr/ portail/jcms/c_2019122/en/gazyvaro-obinutuzumab-type-ii-humanised-anti-cd20-recombinant-monoclonal-antibody. Accessed January 25, 2017.

73. Haute Autorité de Santé TC. Haute Autorité de Santé - LYNPARZA (olaparib), PARP inhibitor; 2015. Available from: http://www.hassante.fr/portail/jcms/c_2038097/en/lynparza-olaparib-parp-inhibitor. Accessed January 25, 2017.

74. Haute Autorité de Santé TC. Haute Autorité de Santé - CYRAMZA (ramucirumab), monoclonal antibody; 2015. Available from: http:// www.has-sante.fr/portail/jcms/c_2048967/en/cyramza-ramucirumabmonoclonal-antibody. Accessed January 25, 2017.

75. Haute Autorité de Santé TC. Haute Autorité de Santé - OPDIVO (nivolumab), anti-PD-1 antibody; 2016. Available from: http://www has-sante.fr/portail/jcms/c_2639665/en/opdivo-nivolumab-anti-pd1-antibody. Accessed January 25, 2017.

76. Haute Autorité de Santé TC. Haute Autorité de Santé - YERVOY (ipilimumab), monoclonal antibody; 2014. Available from: http:/ www.has-sante.fr/portail/jcms/c_1779495/en/yervoy-ipilimumabmonoclonal-antibody. Accessed January 25, 2017.

77. HAS. HAS - Direction de l'Evaluation Médicale, Economique et de Santé Publique Commission: Pertuzumab; 2013. Available from: http:// www.has-sante.fr/portail/upload/docs/evamed/CT-12851_PERJETA INS_Avis2_CT12851.pdf. Accessed December 21, 2016.

78. HAS. Commission de la Transparence: zytiga; 2012. Available from: http://www.has-sante.fr/portail/upload/docs/application/pdf/2012-04/ zytiga_29022012_ct11654.pdf. Accessed December 21, 2016.

79. Wilkens J, Thulesius H, Schmidt I, Carlsson C. The 2015 National Cancer Program in Sweden: introducing standardized care pathways in a decentralized system. Health Policy (New York). 2016;120(12):1378-1382.

80. TLV. TLV: gazyvaro; 2014. Available from: http://www.tlv.se/lakemedel/ Kliniklakemedelsuppdraget/avslutade-halsoekonomiska-bedomningar/ Halsoekonomisk-bedomning-av-Gazyvaro/. Accessed January 25, 2017.

81. TLV. TLV: imbruvica. 2015. Available from: http://www.tlv.se/beslut/ beslut-lakemedel/begransad-subvention/Imbruvica-ingar-i-hogkostnadsskyddet-med-begransning/. Accessed January 25, 2017.

82. TLV. TLV: lynparza; 2015. http://www.tlv.se/beslut/beslut-lakemedel/ generell-subvention/Lynparza-ingar-i-hogkostnadsskyddet/. Accessed January 31, 2017.
83. NT Council. NT-rådets yttrande till landstingen gällande Cyramza (ramucirumab) vid behandling av avancerad magsäckscancer eller adenokarcinom i gastroesofageala övergången; 2015. Available from: http:// www.janusinfo.se/Documents/Nationellt_inforande_av_nya_lakemedel/ Ramucirumab-(Cyramza)-151027.pdf. Accessed December 21, 2016.

84. TLV. TLV: opdivo; 2015. Available from: http://www.tlv.se/lakemedel/ Kliniklakemedelsuppdraget/avslutade-halsoekonomiska-bedomningar/ Halsoekonomisk-bedomning-av-Opdivo-vid-lungcancer/. Accessed January 25, 2017.

85. TLV. TLV: yervoy; 2015. Available from: http://www.tlv.se/lakemedel/ Kliniklakemedelsuppdraget/avslutade-halsoekonomiska-bedomningar/ Halsoekonomisk-bedomning-av-Yervoy1/. Accessed January 25, 2017.

86. TLV. TLV: perjeta; 2013. Available from: http://www.tlv.se/lakemedel/ Kliniklakemedelsuppdraget/avslutade-halsoekonomiska-bedomningar/ halsoekonomisk-bedomning-av-perjeta/. Accessed January 25, 2017.

87. TLV. TLV: Underlag för beslut om subvention -Nyansökan Zytiga (abirateron); 2014. Available from: http://www.tlv.se/Upload/Beslut_2015/ Underlag_beslut_zytiga.pdf. Accessed December 21, 2016.

88. Haglund M, Miller E. Pricing and reimbursement of novel oncology drugs in Sweden. J Mark Access Heal Policy. 2014;2(0).

89. Chafe R, Culyer A, Dobrow M, et al. Access to cancer drugs in Canada: looking beyond coverage decisions. Healthc Policy. 2011;6(3): 27-36.

90. Habl C, Bachner Vienna F. EMINET initial investigation to assess the feasibility of a coordinated system to access orphan medicines; 2011. Available from: http://whocc.goeg.at/Literaturliste/Dokumente/ BooksReports/EMINet_Initial investigationOMP_updated2011.pdf. Accessed February 9, 2017.

91. www.ema.europa.eu [homepage on the internet]. Available from: http:// www.ema.europa.eu/ema/index.jsp?curl=pages/medicines/human/medicines/002799/human_med_001780.jsp\&mid=WC0b01ac058001d124. Accessed December 15, 2016.

92. www.ema.europa.eu [homepage on the internet]. Available from: http:// www.ema.europa.eu/ema/index.jsp?curl=pages/medicines/human/medicines/003791/human_med_001801.jsp\&mid=WC0b01ac058001d124. Accessed December 15, 2016.

93. www.ema.europa.eu [homepage on the internet]. Available from: http:// www.ema.europa.eu/ema/index.jsp?curl=pages/medicines/human/medicines/003726/human_med_001831.jsp\&mid=WC0b01ac058001d124. Accessed December 15, 2016.

94. www.ema.europa.eu [homepage on the internet]. Available from: http:// www.ema.europa.eu/ema/index.jsp?curl=pages/medicines/human/medicines/002829/human_med_001825.jsp\&mid=WC0b01ac058001d124. Accessed December 15, 2016

95. www.ema.europa.eu [homepage on the internet]. Available from: http://www.ema.europa.eu/ema/index.jsp?curl=pages/medicines/ human/medicines/003985/smops/Positive/human_smop_001119. jsp\&mid=WC0b01ac058001d127. Accessed December 15, 2016.

96. www.ema.europa.eu [homepage on the internet]. Available from: http:// www.ema.europa.eu/ema/index.jsp?curl=pages/medicines/human/medicines/002213/human_med_001465.jsp\&mid=WC0b01ac058001d124. Accessed December 15, 2016.

97. www.ema.europa.eu [homepage on the internet]. Available from: http:// www.ema.europa.eu/ema/index.jsp?curl=pages/medicines/human/medicines/002547/human_med_001628.jsp\&mid=WC0b01ac058001d124. Accessed December 15, 2016.

98. www.ema.europa.eu [homepage on the internet]. Available from: http:// www.ema.europa.eu/ema/index.jsp?curl=pages/medicines/human/medicines/002321/human_med_001499.jsp\&mid=WC0b01ac058001d124. Accessed December 15, 2016.

99. NHS England. UK Strategy for Rare Diseases NHS England Statement of Intent. https://www.england.nhs.uk/wp-content/uploads/2014/02/ rare-dis-stat-intent.pdf. Published 2014. Accessed December 20, 2016. 


\section{Publish your work in this journal}

ClinicoEconomics and Outcomes Research is an international, peerreviewed open-access journal focusing on health technology assessment, pharmacoeconomics and outcomes research in the areas of diagnosis, medical devices, and clinical, surgical and pharmacological intervention. The economic impact of health policy and health systems organization also constitute important areas of coverage. The manuscript management system is completely online and includes a very quick and fair peer-review system, which is all easy to use. Visit http://www.dovepress.com/testimonials.php to read real quotes from published authors.

Submit your manuscript here: https://www.dovepress.com/clinicoeconomics-and-outcomes-research-journal 